\title{
AN OUTBREAK OF SMALLPOX \\ IN THE TRUCIAL OMAN STATES
}

\author{
Major P. H. SWINHOE, M.A., M.B., B.Chir., D.R.C.O.G., D.T.M.\&H., R.A.M.C. \\ 16 Commonwealth Field Ambulance, Terendak, Malaysia *
}

SUMMARY: An account is given of an outbreak of smallpox which occurred in the Trucial States in March 1967. The measures which were taken to protect British and Arab servicemen in the area are described, as well as those designed to limit the spread of the disease in the civilian population. Difficulties associated with the implementation of control activities in such a situation are discussed.

\section{Introduction}

In March 1967 a minor outbreak of variola major occurred in the Trucial Oman. This article describes it, but, more particularly, the measures taken in order to prevent its spread to Arab and British Servicemen in the area, a developing country where medical resources were limited. A considerable time has elapsed since the events which are described took place. The area concerned was already in the throes of rapid development in all spheres of life. It is likely, indeed probable, that the changes which have taken place since March 1967 make many of the statements made here no longer applicable. It is written, not as an example of how one should cope with such an occurrence, but in the hope that it might provide some help and guidance to others faced with a similar situation.

\section{The Trucial States}

The Trucial States are seven independent Sheikdoms of South East Arabia, bordering on the Persian Gulf. Their $\mathbf{3 5 0}$ miles of Gulf coastline are what used to be known as the Pirate Coast. Treaties have existed between the United Kingdom and the States since 1820. Originally these treaties were for the purpose of suppressing piracy and the slave trade. In 1835 a Maritime Truce was declared, by which the Sheiks renounced all hostility by sea for the six months of the pearling season. Later it was extended to the Treaty of Peace in Perpetuity between the Sheiks of the different States; from this truce comes the name The Trucial States. The British Government is responsible for the external security and the maintenance of peace within the area, whilst the Sheikdoms retain their independence and complete responsibility for internal government. A Council of the Trucial Rulers co-ordinates the actions of the Sheikdoms on matters of mutual concern.

The States have a combined area of about 32,000 square miles, which makes them a fraction larger than Scotland. Their population is not accurately known, as no census has ever been taken, but it has been estimated to be between 100,000 and 120,000. There is a large immigrant population, mainly from Persia and Pakistan, many of whom have entered the country illegally and may have increased the population figure above the previous estimates. Dubai is the largest town, thought to have a population of about 70,000 , and is the main commercial port.

* Now Lieutenant-Colonel, R,A.M.C. Training Centre, Ash Vale. 


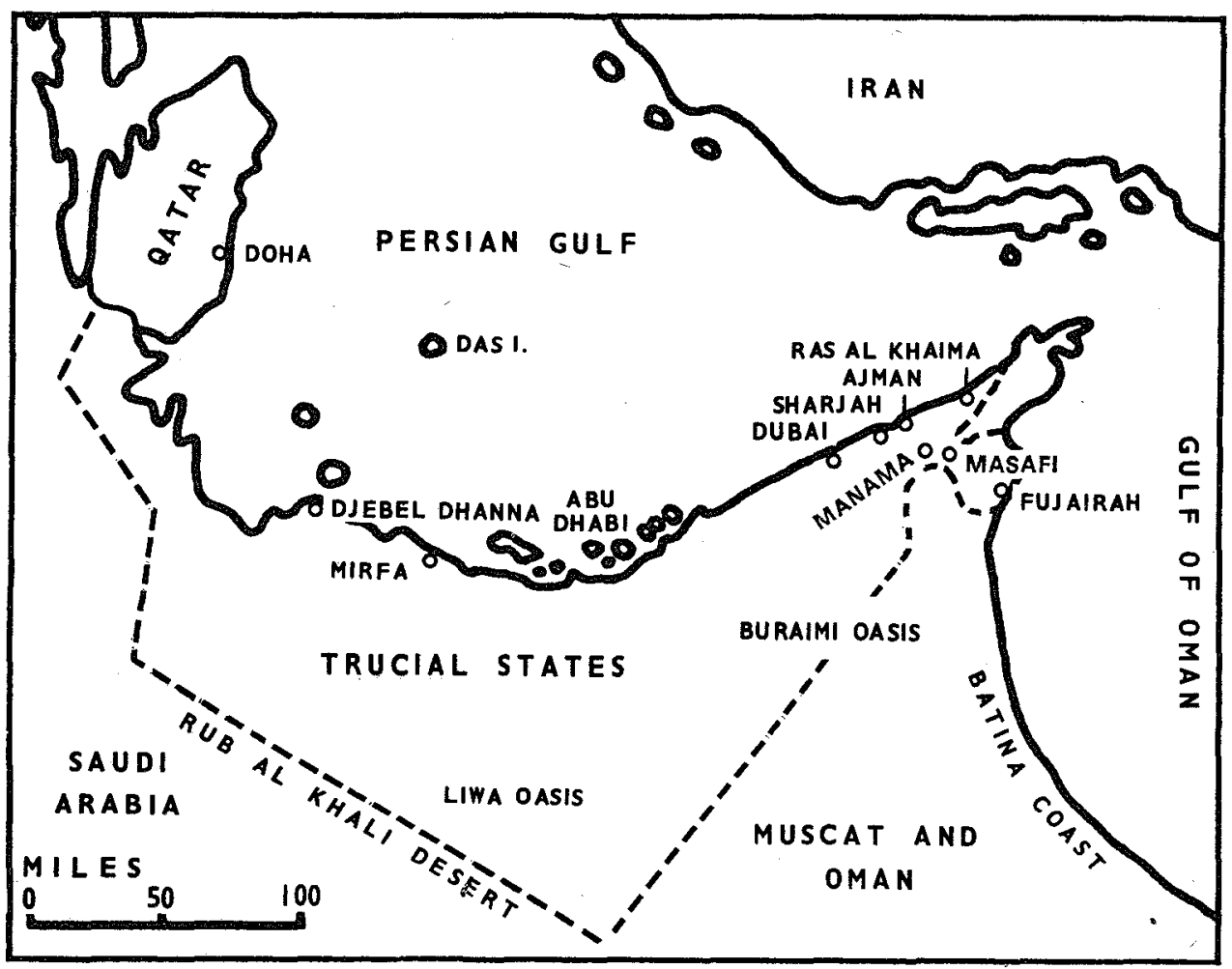

Each State is responsible for its own economic and social development. The discovery of oil in the State of Abu Dhabi, and more recently in Dubai, has increased the revenues of these two States enormously. Exploration for oil is going on in the other States and the concessions for this provide a major source of income. Apart from oil the main products are agricultural (dates, vegetable and hides) and fishing, including pearl fishing, is carried on.

In 1952 the British Government promoted the formation of a British-officered Arab Force, the Trucial Oman Levies, later to become the Trucial Oman Scouts (T.O.S.). They were to be responsible for the internal security and the maintenance of peace and good order. It was as Senior Medical Officer to this force that I came to be in the area at the time of the incident to be described.

\section{Medical resources}

The medical services available in March 1967 were limited. There was no government department especially for health matters. The Senior Civilian Medical Officer of the Trucial States advised the Rulers on matters of public health. There was a civil hospital of about 72 beds in Dubai, the Al Maktun Hospital and the Kuwaiti Medical Mission Hospital of 20 beds. At Buraimi there was a small American Mission Hospital and at Ras al Khaima, a Trucial States Development Scheme Hospital of six beds. Each State possessed a number of dispensaries, staffed by locally trained medical auxillaries, under the control of a travelling medical officer. In four of the main towns there was a Kuwaiti Clinic with a doctor in attendance. 
Apart from the Service medical officers, there were about eighteen doctors in the whole of the Trucial States in 1967; thirteen in government employment, two mission doctors, one employed by an oil company and two in private practice.

\section{Communications}

Communications in the area were, in the main, by rough tracks of sabkha, sand, or gravel, a few of which were graded. At the time of the outbreak there was one metalled road, between Sharjah and Dubai, a distance of about sixteen miles.

\section{Service deployment}

Service deployment in March 1967 consisted of Royal Air Force (R.A.F.), Sharjah and the T.O.S., contained within a perimeter approximately one mile from the town of Sharjah. Within the camp there was a small R.A.F. sick quarters, containing ten beds, and a larger medical reception station of thirty beds, equipped with laboratory and radiological facilities. This catered for the Arab troops and a certain number of Arab civilians, admission of whom depended on bed availability. When the outbreak of smallpox occurred there were two medical officers within the camp, the Senior Medical Officer of the T.O.S. and the Medical Officer of R.A.F., Sharjah, subsequently reinforced by a third medical Officer.

Whilst the T.O.S. Headquarters and base units were located within Sharjah camp, squadrons were maintained at Buraimi, Manama, Masafi, and Mirfa, respectively 100 , 40,50 , and 125 miles from the base. At each of these outstations a small medical centre was staffed by a non-European medical orderly. These orderlies dispensed simple medicines to the troops under their care and could get in touch, by radio, with the medical officer at base and call for assistance. They could, after consultation, evacuate by road or by air the more seriously ill patient. These orderlies also provided, within their capabilities, assistance to the local population.

At the time of the outbreak, over 2,000 civilian workmen were employed at the base camp on the building works necessitated by the proposed build up of British forces in the Persian Gulf, following the withdrawal from Aden. These were in addition to the civilian labour normally employed.

\section{Record of Cases}

The smallpox outbreak

March 8th 1967. An Indian male was admitted to the civilian Al Maktun hospital in Dubai with an undiagnosed rash.

March 10th. Two days after the first case, a second Indian male was admitted to the hospital in the early pustular stage of benign semi-confluent smallpox. By this time the first case to be admitted was also diagnosed as having the disease.

Both these patients had entered the Trucial States illegally by landing from a dhow at Ras al Khaima, on 21 st February, along with approximately 48 other people. They embarked at Bombay on 10th February. All the passengers from this dhow had dispersed on landing and were thought to have made for Sharjah and Dubai.

March 13th. Two further cases were admitted to the Al Maktun hospital. These were Pakistani children, who had landed from a second dhow at Ajman on 21st February, 


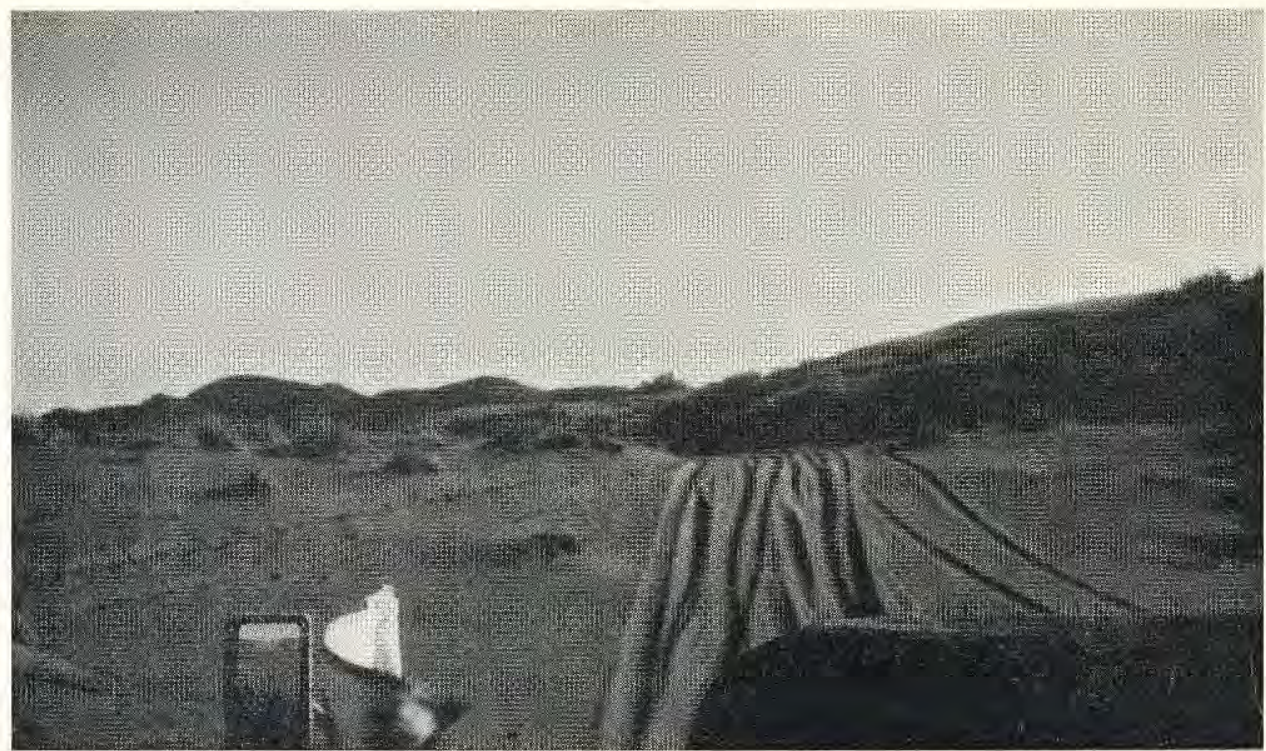

Gravel track between Manama and Masafi.

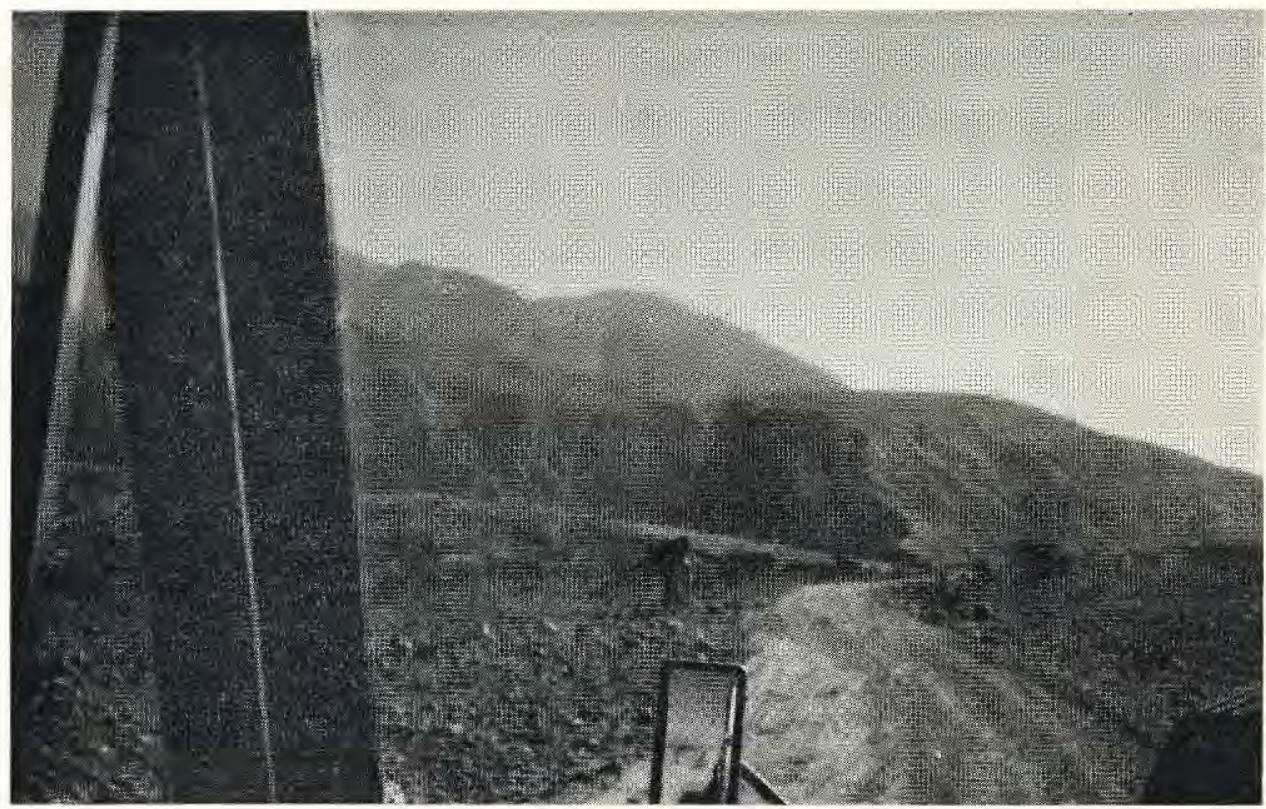

Sand track between Buraimi and Manama Oasis.

on the same day that the first dhow was landing the other cases. The vessel was said to have capsized on landing and the exact number of passengers, or their whereabouts, was unknown. 
The diagnosis of smallpox was confirmed on 16th March from vesicular fluid taken from one of the patients from each dhow. These were the only cases who had a diagnosis confirmed by laboratory means.

Seven further known cases occurred:-

March 18th. A child from Sharjah died from the disease. No connection could be established with any of the other cases.

March 24th. A Pakistani male was admitted on the 12th day of the disease and was traced to the dhow which disembarked its passengers at Ajman.

April 19th. An Arab child was admitted, also at the 12th day of the disease and was found to live in the same area as the last mentioned case, although no definite contact was established.

Four further cases occurred, all children who were related and in which contact with previous cases was proved. One of these subsequently died.

A total of eleven cases were admitted to hospital, two of whom died.

\section{Action taken by the services}

The Senior Medical Officer, T.O.S. was first informed of the possible occurrence of two cases of smallpox at $1100 \mathrm{hrs}$ on 10 th March. He was asked by the Medical Superintendent at the Al Maktun Hospital, Dubai, if he would view the suspected cases. At the meeting, the Civilian Medical Officer enquired as to the immediate availability of smallpox vaccine from Service sources. A signal was immediately sent to Headquarters, Middle East Command, notifying the occurrence of smallpox in Dubai. At a consultation between the two Service medical officers it was agreed that the ideal initial precautions would be:-

The isolation of Sharjah Base by:-

Confining all the British troops to the camp.

Withdrawing the "living out" Arab soldiers from the town of Sharjah and keeping them in the camp.

Excluding civilians (apart from those living within the camp) from the camp, including the civilian labour force.

Checking the vaccination state of all troops and resident civilians within the camp and bringing their state of vaccination to within one year's validity.

At a subsequent meeting with the Commander, T.O.S. and the Officer Commanding, R.A.F., Sharjah, it was pointed out that certain factors made the implementation of these requirements impracticable. There would be great difficulty in confining Arab troops to camp, when their families were living in town. Also, the redeployment of British servicemen within the Persian Gulf necessitated the continuation of the civil works without delay; so the exclusion of the civilian labour from the camp was not operationally feasible. It was therefore agreed:-

To confine all British troops to camp, except those on essential duties. Troops were allowed out of the camp on water duties, refuse disposal, the purchase of essential stores, and the truck drivers on duty details.

To confine all Arab troops to camp, except those on the above 
duties and those who normally lived out. The latter would be allowed to enter camp each morning, when reporting for duty, and to leave each night.

To carry out a daily medical inspection of all soldiers and civilian employees entering the camp.

To exclude all other persons from the camp.

To place the town of Dubai out of bounds to all Arab and British troops.

To check the vaccination state of all troops and to vaccinate all those without documentary evidence of vaccination during the last twelve months. All civilian employees entering the camp were to be vaccinated as soon as vaccine supplies allowed; admission to the camp was to be refused to those who could not produce documentary evidence of vaccination within the last twelve months.

To check the vaccination state of all aircrews and their passengers staging through R.A.F., Sharjah and to vaccinate those unable to satisfy the twelve month validity period.

To apply for 100,000 doses of smallpox vaccine through Service channels for a mass civilian vaccination programme.

In order to control entry and egress from the camp, the gates were opened only at specific times. At one point of the perimeter where civil workings had necessitated the removal of the boundary fence, patrols were used to prevent entry and exit. All personnel entering or leaving camp on essential business were required to possess a pass.

By 12th March (thirty-six hours after notification of the outbreak) all the troops, Arab and British, at Sharjah base and all civilian employees had been vaccinated to within the stipulated limit. By 15th March all Arab and British troops at T.O.S. outstations had been similarly vaccinated.

On 15th March a Medical Adviser from the World Health Organisation (W.H.O.) arrived in the Trucial States in order to advise the civilian authorities on the measures necessary to control the outbreak. The opportunity was taken to obtain his advice in relation to the action taken by the Service medical officers in the Sharjah base. He described the Service action as a "rigidly and well executed plan ". He felt that the dangers to Service personnel were at this stage, three days after having vaccinated to a twelve month validity, considerably reduced, bearing in mind that 64,000 vaccinations had been completed in Dubai.

As a result of this advice, restrictions were lifted on Service personnel, although Dubai remained out of bounds to troops. The inspections of civilian labour entering the camp were continued, in order to detect overt cases and to vaccinate any persons without documentary evidence of vaccination within the last twelve months.

On March 18th, when the child from Sharjah town died from smallpox, the W.H.O. adviser was again consulted and suggested that this development warranted no change in the precautions already taken.

Twenty days after the occurrence of the first case of smallpox in Dubai a request 
was made to the medical officers, by the Commander, T.O.S. and the Commanding Officer, R.A.F., Sharjah, that relaxation of medical inspection of civilian employees entering the camp daily should be allowed. The reasons for the request were that medical inspection was delaying the civil workings in the camp, and the difficulties arising over the provision of sufficient men to cover gate control duties.

At this time, the last case of smallpox notified in Dubai on 24th March, was in the twelfth day of the disease. It was therefore advised that medical inspection of the workers should continue until 8th April, fourteen days after the isolation of this case, provided no further cases were notified.

Medical inspection of the civilian workers entering the camp was withdrawn on 8th April. These inspections were not reintroduced when a further four cases of smallpox were isolated in Dubai on 17th May. It was felt that by this time the civilian vaccination state was sufficiently high to provide little risk to Service personnel, themselves protected by vaccination.

On 15th June, twenty-eight days after the occurrence of the last cases of smallpox in Dubai, the town was declared to be no longer a locally infected area, the town of Sharjah having been similarly declared free of infection on 15th April.

\section{Supply of vaccine}

At the beginning of the outbreak, on 10th March, Service vaccine stocks at Sharjah amounted to approximately 400 doses. An initial request by the civilian hospital in Dubai for 200 doses of calf lymph was met from this reserve and was used in the protection of the patients and staff of the Al Maktun Hospital and the Police Force of Dubai, who were utilised in tracing contacts. It is worth mentioning that the standard 25-dose pack of calf lymph, when used in sufficient quantity, would appear to allow virtually two to three times the number of vaccinations to be performed without noticeable fall in the number of takes.

The civilian authorities asked for a further 100,000 doses of calf lymph from Service sources in order to carry out a mass vaccination programme. This request was cancelled when a neighbouring State promised 50,000 doses immediately. This offer never materialised and as a result, the mass vaccination programme of the civilian population was delayed for four days, until 15,000 doses were received from Dhahran. The request for 100,000 doses of Service vaccine was renewed when it was realised that the original offer of 50,000 doses was not to be forthcoming. The total stock of 500 doses, from Army Medical Equipment Depot, Aden, was received for Service use on 11th March. On 14th March 30,000 doses (part of the 100,000 requested from Service sources) arrived for civilian use. The balance of 70,000 was to be dispatched as soon as it arrived from the United Kingdom.

Fearing the occurrence of an "explosive epidemic", Her Britannic Majesty's Political Agent in Dubai had requested the services of a W.H.O. Smallpox Expert, who arrived in the Trucial States on 15th March, bringing 100,000 doses of vaccine with him. The balance of 70,000 doses promised from Service sources was therefore cancelled.

After the initial scarcity of vaccine, there was by 15 th March sufficient to vaccinate between 290,000 and 435,000 persons, bearing in mind the fact that it is possible to obtain 50-75 doses per 25 dose vial. The population of the entire Trucial States was 
probably less than 150,000 at the time of the outbreak. There can be little doubt that there was wastage of vaccine. To give an example, 5,000 doses were dispatched to the Batina Coast on the 15th March and when this area was visited on 21st March, a substantial quantity of this was found unused and unrefrigerated and therefore useless. The fact that promised vaccine failed to arrive delayed the civilian vaccination programme by four days.

\section{The vaccination programme}

The mainstay in the control of a smallpox outbreak in an area such as the Trucial States must be mass vaccination. At the time of the outbreak there was no public health authority, an overall low standard of hygiene and difficulty in discovering and isolating smallpox cases and in tracing their contacts.

By 11th March, twenty-four hours after the clinical diagnosis of the first case, all British personnel in the Sharjah Base had been vaccinated to within the prescribed limit of twelve months, and by 12th March all Arab soldiers had been similarly dealt with. Five days after the clinical diagnosis of the first case, all personnel at the outstations had been vaccinated where necessary and also a Company of K.O.R.B., training at Manama. It was known that eight R.A.F. cadets from Cranwell were on tour in the Trucial States and were thought to be in the Batina Coast area. Contact was made with them by radio and a rendezvous kept by helicopter, in order that they could be vaccinated.

As a matter of some urgency, the civilian labourers employed in the Sharjah Base, by the Ministry of Public Buildings and Works and by local civilian firms, had to be vaccinated. These men entered the camp daily for work and were inspected by the medical officers and R.A.M.C. and R.A.F. medical personnel at the gates each morning. Vaccination was begun on 12th March, when over 2,000 were vaccinated as part of the morning inspection. A means of documentation had to be devised, particularly as the civilian firms continued to take on fresh casual labour each morning. For this reason vaccination had to continue each day, together with the check on those already vaccinated, to ensure that no unprotected worker entered the camp. The solution was found by stamping their work/time cards, as without these the employees received no pay and so were unlikely to lose them or lend them to others.

Five days after the outbreak commenced, it was possible to begin vaccination in support of the civilian authorities, by vaccinating the families of Arab soldiers and civilians living close to the Sharjah Base and to the T.O.S. outstations.

The risk of importing further cases of smallpox from India and Pakistan was a constant one. Landings on the Batina Coast occurred, but fortunately only one route was possible from there to the more populous areas and this was patrolled by the T.O.S. Masafi Squadron. All persons using this route were medically inspected and vaccinated. Landings also occurred on the Northern coastline, but were reported by the local population, who by this time were aware of the danger. Over 200 immigrants were rounded up at Ras al Khayma, medically inspected and vaccinated.

Civilian doctors had set up centres for vaccination in Dubai and Sharjah and had sent vaccination teams into the surrounding areas. Assistance was given by the Service personnel in support of this programme and wide areas were covered by landrover, helicopter, and fixed wing aircraft. The local knowledge of the Scouts and their radio communications proved extremely useful in this work. It was even possible to send a 


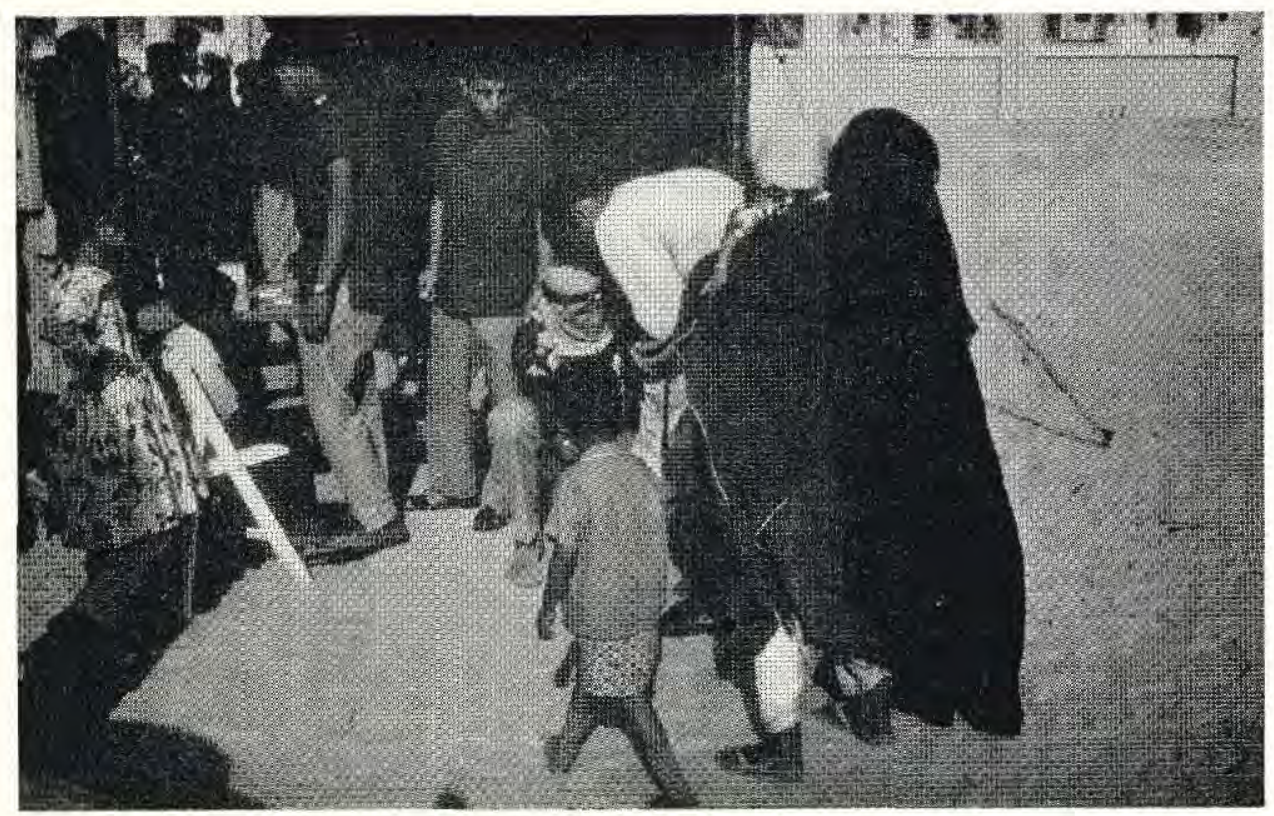

Vaccination of the local population at Sharjah.

team of vaccinators into the Liwa Hollows, a chain of oases in the deep sands, in order to vaccinate the isolated communities. It is probable that Service medical personnel vaccinated more than 12,000 people. Although this figure in itself does not seem particularly large, many of those vaccinated were in places difficult of access.

During the course of the outbreak, several requests were made by the local population in remote areas for assistance for patients suffering from smallpox. Although none of these calls resulted in the finding of a case of the disease, each had to be investigated, treatment given and vaccination carried out.

Service tentage, gowns, masks, sheets, blankets and medical stores were provided for the isolation hospital which was set up in Dubai.

\section{Discussion}

The difficulties experienced in dealing with this smallpox outbreak in the Trucial States were many, but perhaps the most important, from which stemmed many of the others, was the lack at the time of a controlling and co-ordinating public health service.

After a few days a doctor was appointed to take charge of the civilian medical services, but his task was often hampered by lack of co-operation and conflicting sectional interests. There was no central control of the limited medical aid and, as a result, the effectiveness of the measures undertaken was often hampered. It would be fair to say that there was some breakdown in the principle of concentrating the vaccination programme in the immediate area of the outbreak, that is to say, Dubai and Sharjah and then extending it to include the adjoining areas as vaccine supply and vaccinators allowed. 
The outbreak was caused by the importation of smallpox by illegal immigrants from India and Pakistan. The extent of the Trucial States coastline made it impossible to prevent illegal landings and so there was continual risk of further cases being brought into the country. In addition, Indians and Pakistanis, who are familiar with the seriousness of the disease, may have hidden cases from the medical authorities. Being present in the country illegally, they may have felt that declaring cases would lead to their imprisonment or deportation. The full extent of the outbreak was therefore possibly never known. Contacts were difficult to trace and the numbers presenting for vaccination may have been reduced.

The only isolation hospital in Dubai was an old building previously used for lepers and totally unsuitable for smallpox cases. A mental hospital, consisting of a few small wards and initially without piped water, electricity, sewage, facilities for food preparation, or telephone was taken over. It was also too close to the inhabited areas. Despite its drawbacks the standard of nursing care afforded by the European sister and her assistants was of a high order. Contacts were held in tented accommodation, situated well away from the town, but the main difficulty, apart from providing sanitation, water and cooking facilities, was the actual detention of the contacts. Since they did not feel ill they did not see the point of being confined. Their isolation for the stipulated period had to be enforced and a perimeter of dannert wire erected.

Diagnosis was made difficult for two reasons. Firstly because there was a concurrent chickenpox epidemic, both among civilians and the Arab servicemen. Secondly because vaccination could result in the occurrence of modified smallpox. Cases of suspected chickenpox required very careful assessment.

Vaccine supply was an initial problem, delaying the commencement of the civilian programme of vaccination. Later a surplus occurred and there was vaccine wastage due to inadequate storage facilities and ignorance of the need to store under refrigerated conditions. Despite the stamping of the work cards of the civilian labour force in the Sharjah Base when they had been vaccinated, it was possible that a number never were vaccinated. Cards were stolen and interchanged and new labour was continually being engaged.

Difficult terrain and poor communications, particularly in outlying areas, were a major problem, but here the local knowledge and excellent signals communication of the Scouts made things a great deal easier. In addition the assistance given readily by Army helicopters and R.A.F. aircraft was of great value.

This outbreak of smallpox was fortunately limited in extent and was probably controlled by mass vaccination. Isolation of cases and known contacts played a significant part in preventing further spread of the disease.

The ever present problem of illegal immigration into the Trucial States supplied a constant threat of the introduction of other cases of smallpox. Assuming that immigration continues to be uncontrolled, further importation of smallpox could occur at any time from an endemic area. Control of a new outbreak would inevitably mean further mass vaccination campaigns, since there is no means of knowing which members of the population have been vaccinated. The population of the Trucial States is unknown and a simple census is a necessary requirement. Immigration control, with a medical check of immigrants, would reduce the risks of imported disease, but would do little to relieve the immense problem of the illegal immigrant. 